\title{
OPTIMISATION OF SQUALENE RECOVERY FROM PALM OIL BY-PRODUCT USING INTEGRATED SCCO 2 -PRESSURE SWING
}

\author{
NORHIDAYAH SULEIMAN*; BADLISHAH SHAM BAHARIN*; MD ZAIDUL ISLAM SARKER ${ }^{\star *}$; \\ SEYED HAMED MIRHOSSEINI* and MOHD HELMI ALI ${ }^{\star}$
}

\begin{abstract}
Squalene is used as an ingredient in functional foods, pharmaceuticals, and cosmetics. Due to the limitation of squalene availability from predominant source which is shark liver oil and to sustain the environment by fully utilising the by-product of palm oil, an effort has been made to find a potential source of squalene as an alternative to shark liver oil. The motivation for this work is to optimise its extraction from an alternative source, a palm oil by-product known as palm fatty acid distillate (PFAD), using supercritical carbon dioxide $\left(\mathrm{sc}_{-} \mathrm{CO}_{2}\right)$ with the aid of a pressure swing technique. The measurements were performed using a sc-CO extraction in a fixed bed at temperatures of $40^{\circ} \mathrm{C}, 50^{\circ} \mathrm{C}$, and $60^{\circ} \mathrm{C}$, pressures of 20,30 and $40 \mathrm{MPa}$, and holding times of 20, 30 and 40 min; high performance liquid chromatography (HPLC) was used for squalene content analysis, optimised with a central composite design using research surface methodology (RSM). The second-order polynomial mathematical model adequately fitted the experimental results. The maximum squalene content from the model was predicted to be $356.24 \mathrm{ppm}$ under the set of conditions with pressure of $23 \mathrm{MPa}$, temperature at $40^{\circ} \mathrm{C}$, and 20 min holding time.
\end{abstract}

Keywords: squalene, palm fatty acid distillate, $\mathrm{sc}-\mathrm{CO}_{2}$, pressure swing technique.

Date received: 27 February 2018; Sent for revision: 6 April 2018; Received in final form: 24 July 2018; Accepted: 9 October 2018.

\section{INTRODUCTION}

The increasing number of uses of squalene in multiple global industries is alarming. Squalene is commonly associated with health benefits, and has pharmaceutical, cosmetic and food functional applications. For instance, it is used as an antioxidant in skin and eye creams, and as a bactericidal and fungicidal agent (Bhattacharjee et al., 2012). In

\footnotetext{
* Department of Food Technology,

Faculty of Food Science and Technology,

Universiti Putra Malaysia, 43400 UPM Serdang,

Selangor, Malaysia.

E-mail: su_hidayah@upm.edu.my

** Kulliyyah of Pharmacy, International Islamic University Malaysia, Jalan Sultan Ahmad Shah, Bandar Indera Mahkota, 25200 Kuantan, Pahang, Malaysia.

₹ School of Management, Faculty of Economics and Management, Universiti Kebangsaan Malaysia, 43600 Bangi,

Selangor, Malaysia.
}

addition, squalene is commonly used as a natural moisturiser or emollient agent in personal care products (Vázquez et al., 2007). As squalene is not very susceptible to peroxidation, it acts as a quencher of singlet oxygen in the skin (Ryan et al., 2007), and so is used, in dietary form, to protect human skin from lipid peroxidation caused by exposure to ultraviolet and other sources of oxidative damage.

However, the supply of squalene is limited. It is predominantly derived from animal products. Shark liver oil is the primary source of squalene, as it is approximately $80 \%$ squalene (Fornari et al., 2008). However, sharks are protected and this supply is not sustainable. Therefore, it is necessary to find alternative sources of squalene (Bhattacharjee et al., 2012). One such source is plant oils, for instance palm oil, wheat germ oil, rice bran oil, amaranth oil, and olive oil (Bhattacharjee et al., 2012; Bondioli et al., 1992; Fornari et al., 2008; Vázquez et al., 2007; 
Westerman et al., 2006). Squalene can be derived from palm fatty acid distillate (PFAD). PFAD is a low-value by-product obtained from the physical refining of palm oil during the fatty acid stripping and deodorisation stages (Al-Darmaki et al., 2012; Chin et al., 2012; Suleiman et al., 2012; Hosseini et al., 2015). In Malaysia, 649459 t of PFAD were produced from the processing of 19.96 million tonnes of crude palm oil (CPO), accounting for $3.25 \%$ of the waste from the refining of a tonne of palm oil (MPOB, 2016). PFAD is commonly used as a feedstock for other industries, for example in the production of animal feeds and oleochemicals (Boonrod et al., 2017; Haslenda and Jamaludin, 2011). Even though, PFAD can be used in biorefinery, however, the main limitation is the transportation cost between plantation area and biorefinery (Koncsag et al., 2012). Squalene has been recovered from a by-product of the palm oil industry (Al-Darmaki et al., 2012; Gapor Md Top, 2010). Moreover, the use of an industrial by-product can increase profits and reduce the need for waste disposal (Riggi and Avola, 2008).

PFAD is $72.7 \%-92.6 \%$ free fatty acid (FFA), plus non-glycerides (1\%-2.5\%); the non-gylcerides are highly valuable phytochemicals, such as vitamin E (tocopherols) and squalene (Al-Darmaki et al., 2012; Gapor Md Top, 2010), which have wide applications in the food, cosmetics, and pharmaceuticals industries (Boonrod et al., 2017). The use of PFAD as an alternative source of such phytochemicals can lessen operation costs and sustain the market price of the end-products (Haslenda and Jamaludin, 2011).

The extraction and purification of squalene from PFAD using conventional methods like solvent extraction and steam distillation require many steps (Zaidul et al., 2007). Even though, the extraction of squalene using organic solvents might produce high extraction yield, however, this technique will give a severe impact towards environment (Corzzini et al., 2017). The use of toxic solvents such as hexane and chloroform in the conventional methods can be harmful to health and the environment (Mubarak et al., 2015). Furthermore, Ille (2000) argued that conventional methods tend to lose valuable volatile compounds during vacuum evaporation of the solvent, and the difficulty of removing the solvent from extracts may impact the yield and quality of the total production.

Extraction of valuable compounds using the conventional technology contributed to an intensifying problem of theenvironment. Limitations of using conventional extraction techniques can be overcome by using compressed gas as a solvent in the extraction process (Ille, 2000). Supercritical carbon dioxide $\left(\mathrm{sc}-\mathrm{CO}_{2}\right)$ is an emerging tool for extraction due to its superior properties. Interestingly, for sc$\mathrm{CO}_{2}$ there is no distinction between the liquid and gas phases. The supercritical fluid has liquid-like density and gas-like viscosity (Brunner, 2005), and its fluid properties can be controlled simply by changing the temperature or pressure of the system without the need to cross any phase boundaries. Another important characteristic of the supercritical fluid is its dissolving power, which is dependent on its density, and this can be varied continuously by manipulating the temperature and pressure of the system in the vicinity of the critical point (Brunner, 2005). This in turn means that extraction times can be shorter and higher yields can be obtained, even for materials of high molecular weight, like waxes, paraffin, lipids, and resins (Azmir et al., 2013). A small isothermal rise in pressure near the critical point will significantly increase the fluid density (Brunner, 2005). However, this behaviour lessens further away from the critical point (Brunner, 2005).

Various researchers in the literature have studied the squalene recovery from olive oil deodoriser distillate (Paolo et al., 1993; Vázquez et al., 2007). Leng et al. (2008) studied the separation of squalene from PFAD using adsorption chromatography. The recovery of squalene from PFAD using $\mathrm{sc}-\mathrm{CO}_{2}$ was proposed in a previous paper (Suleiman et al., 2012). An extensive study on the supercritical fluid extraction and fractionation of squalene from PFAD using compresses carbon dioxide was done by Al-Darmaki et al. (2012). Herein, the focal aim is to investigate and optimise the recovery of squalene using $\mathrm{sc}-\mathrm{CO}_{2}$ integrated to a pressure swing technique in order to improve the extraction process and increase the yield (Zaidul et al., 2007). Pressure swing technique consists of pressurisation and depressurisation steps during the process of extraction using $\mathrm{sc}-\mathrm{CO}_{2}$. This technique initially has been proposed for the separation of cashew nut shell liquid from cashew nut shells (Smith Jr et al., 2003). The findings showed the yields had increased when applying pressure swing technique rather than constant pressure extraction and also reduced the consumption of $\mathrm{CO}_{2}$ in the extraction process (Smith Jr et al., 2003). Zaidul et al. (2007) also investigated the use of pressure swing technique with $\mathrm{sc}-\mathrm{CO}_{2}$ in the separation of palm kernel oil from palm kernel and found out the yield was about double that obtained with continuous extraction. To our knowledge, there are no studies devoted on the squalene recovery from PFAD using $\mathrm{sc}-\mathrm{CO}_{2}$ with pressure swing technique.

\section{MATERIALS AND METHODS}

\section{Materials and Analytical Methods}

PFAD (iodine value, IV, $64.3 \mathrm{~g} \mathrm{I}_{2} / 100 \mathrm{~g}$ oil; slip melting point, $\mathrm{SMP}, 47.5^{\circ} \mathrm{C}$ ) in semi-solid phase was supplied by Golden Jomalina Food Industries Sdn Bhd, Teluk Panglima Garang, Selangor, Malaysia. 
Squalene with a purity of $98 \%$ was purchased from Sigma Aldrich. The $n$-hexane and $100 \%$ acetonitrile were purchased from Merck, Darmstadt, Germany. Commercial immobilised Candida antartica lipase (Novozyme 435) was purchased from Novo Nordisk, Bagsvaerd, Denmark. Carbon dioxide with a purity of $99.9 \%$ was purchased from Moxlinde Gases Sdn Bhd, Petaling Jaya, Selangor, Malaysia. All chemicals used were either of analytical or high performance liquid chromatography (HPLC) grades. Squalene content was measured by an HPLC analyser equipped with a UV detector (SPD$10 A V$ VP UV Detector; Shimadzu) from Agilent Technologies. The analytical column was kept at $35^{\circ} \mathrm{C}$ and the UV-Vis detector was set at $208 \mathrm{~nm}$. Identification was through spiking with a squalene standard solution and quantification was based on the use of a standard curve.

\section{Experimental Set-up: Supercritical Fluid Extraction}

A schematic diagram of the experimental set-up is presented in Figure 1. The maximum operating temperature and pressure were $100^{\circ} \mathrm{C}$ and $50 \mathrm{MPa}$, respectively. A high pressure pump (Jasco PU-1580 Intelligent HPLC Pump, Jasco Inc., Easton, USA) was fitted with a cooling jacket for the $\mathrm{CO}_{2}$ supply. To cool the pump head, a low temperature bath circulator (Model 631D; Tech-Lab Manufacturing Sdn Bhd, Selangor, Malaysia) was used with a circulating mixture of $(50 \%, \mathrm{v} / \mathrm{v})$ ethylene glycol and deionised water. The volume of the extractor vessel (Model EV-3; Jasco Inc., Easton, USA) was $50 \mathrm{ml}$ and the water bath was set to the desired temperature.

In this set-up, there were three independent variables: pressure $(20,30,40 \mathrm{MPa})$, temperature $\left(40^{\circ} \mathrm{C}, 50^{\circ} \mathrm{C}, 60^{\circ} \mathrm{C}\right)$, and holding time $(20,30,40 \mathrm{~min})$ for a 90 min dynamic extraction time. The liquid $\mathrm{CO}_{2}$ was compressed to the desired pressure and continuously pumped through the extractor at 3 $\mathrm{ml} \mathrm{min}^{-1}$. The temperature was controlled using a water bath. Figure 2 illustrates the experimental design. At a given pressure and temperature, the extractor containing PFAD was pressurised (step P1, Figure 2) with compressed $\mathrm{CO}_{2}$ within $5 \mathrm{~min}$, held for $20 \mathrm{~min}$ at the given conditions (step H1, Figure 2), and depressurised within $10 \mathrm{~min}$ (step D1, Figure 2). This pressure swing step was repeated three times before continuing with the continuous extraction for $60 \mathrm{~min}$ (step P4-C, Figure 2). Only the depressurisation steps and continuous extraction were taken into account for the extraction time, hence, the total extraction was $90 \mathrm{~min}$. Note that the compressed $\mathrm{CO}_{2}$ was not consumed during the holding steps $\left(\mathrm{H}_{1}, \mathrm{H}_{2}, \mathrm{H}_{3}\right)$. The yield was determined for each depressurisation step and at the end of the continuous extraction period.

\section{Experimental Design}

RSM was applied to optimise the process parameters for the sc- $\mathrm{CO}_{2}$ extraction of squalene from PFAD with the aid of a pressure swing

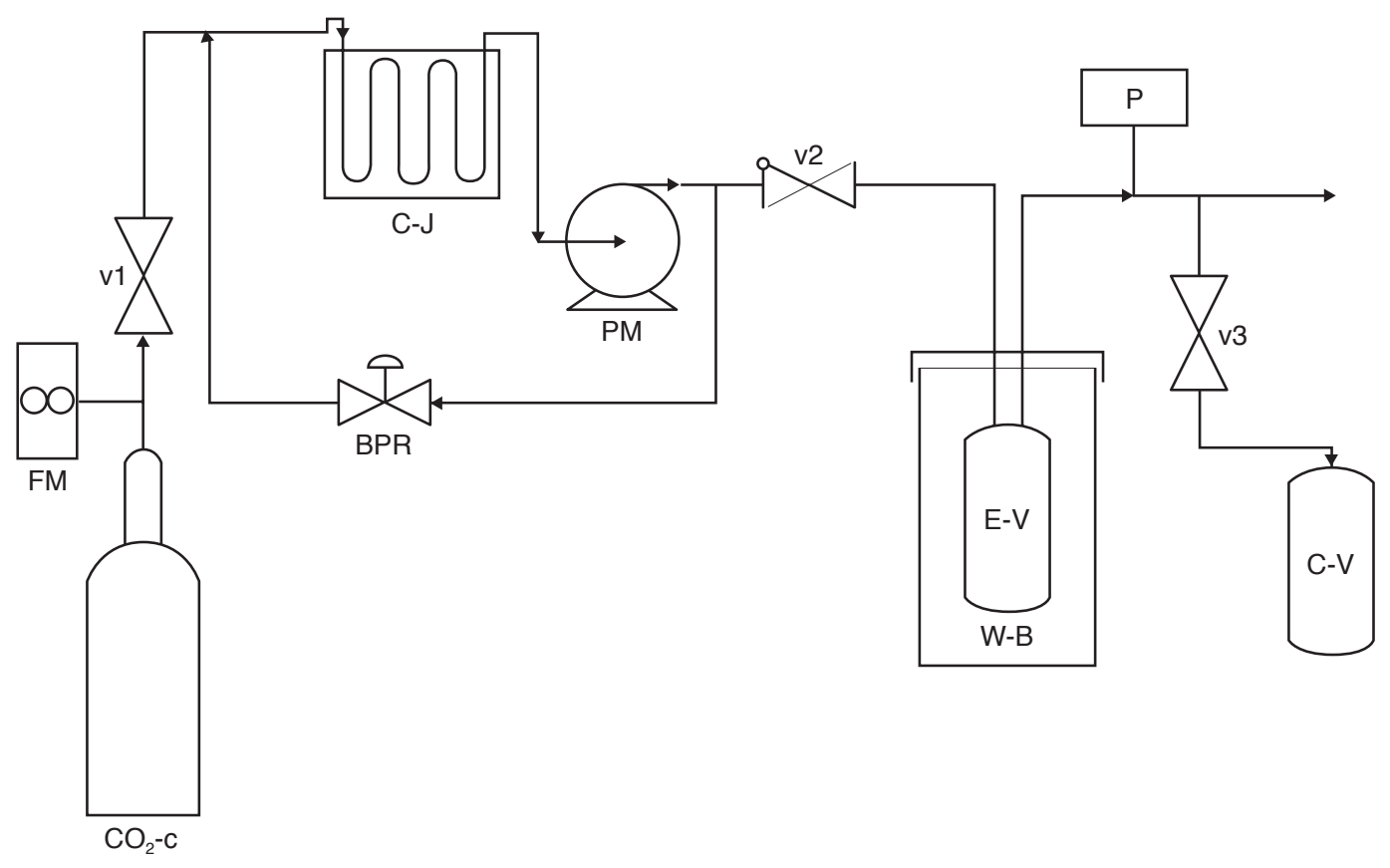

Figure 1. Supercritical carbon dioxide $\left(\mathrm{sc}-\mathrm{CO}_{2}\right)$ controlled set-up with the aid of a pressure swing technique. The components are labelled as follows: $\mathrm{CO}_{2}-\mathrm{C}$ (carbon dioxide cylinder); FM (flow meter); v1 and v3 (gate valve); v2 (check valve); C-J (cooling jacket); PM (pump); BPR (back pressure regulator); $E-V$ (extractor vessel); $W-B$ (water bath); $P$ (pressure gauge); $C-V$ (collector vessel). 


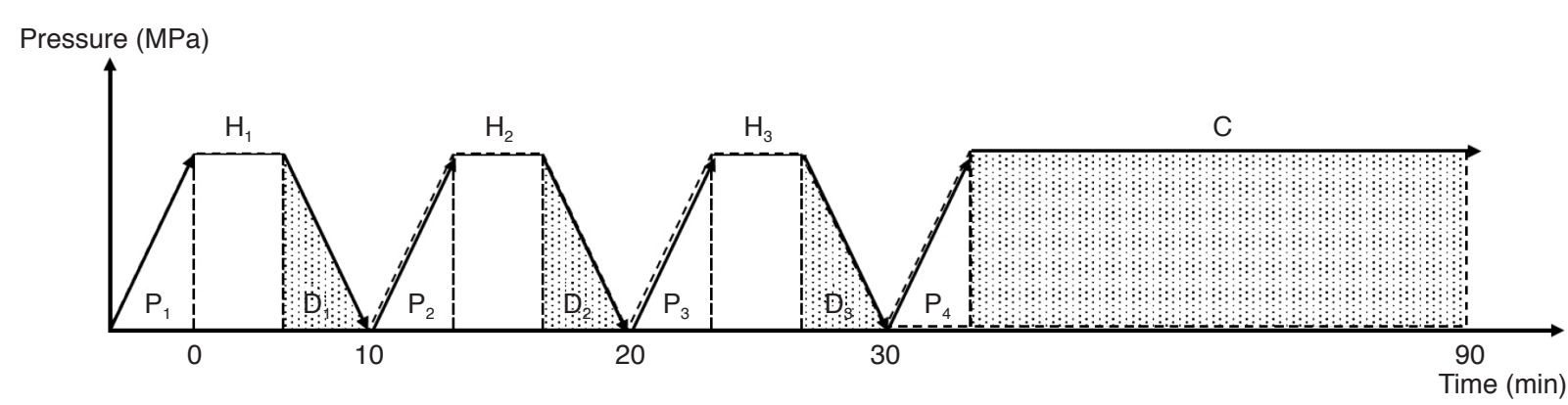

Figure 2. Experimental design for the extraction of squalene from palm fatty acid distillate (PFAD) using supercritical carbon dioxide $\left(\mathrm{Sc}_{-}-\mathrm{CO}_{2}\right)$ with the aid of a pressure swing technique. The steps are labelled as follows: $P_{1}, P_{2}, P_{3}, P_{4}$ : pressurisation steps of 5 min each; $H_{1}, H_{2}, H_{3}$ : holding steps of 20 min; $D_{1}, D_{2}, D_{3}$ : depressurisation steps of 10 min each (total extraction time is $30 \mathrm{~min}$ ), which combined is the overall pressure swing step; C: continuous extraction for $60 \mathrm{~min}$.

technique. The pressure $\left(X_{1}\right)$, temperature $\left(X_{2}\right)$, and holding time $\left(\mathrm{X}_{3}\right)$ were independent variables studied to optimise the squalene yield (Y). The independent variables were converted to range from -1 up to 1 for the appraisal of factors. Table 1 lists the coded levels of the independent variables used in the RSM. The coded levels of the independent variables were chosen based on the preliminary experimental results. In order to minimise the effect of unexplained variability in the observed response due to extraneous factors, all experiments were performed in random order (Liu et al., 2009).

Herein, the experimental design was set up according to a central composite design (CCD). This design consists of three parts: (1) a full factorial or fractional factorial design; (2) an additional design, often a start design in which experimental points are at distance $\alpha$ from its centre; (3) a central point (Bezerra et al., 2008). CCD was chosen to ensure the availability of all information for analysis and a star design with three central points, as shown in Table 2. MINITAB release 14 was used for multiple regression analysis, analysis of variance (ANOVA), and to process the optimisation point. A quadratic polynomial regression model was used to predict response variables, $Y$, as a function of the parameters (independent variables) according to Equation (1):

$$
\mathrm{Y}=\beta_{0}+\sum \beta_{i} X_{i}+\sum \beta_{i i} X_{i}^{2}+\sum \sum \beta_{i j} X_{i} X_{j}
$$

where $\beta_{0}$ is an intercept, $\beta_{i}, \beta_{i j}$ and $\beta_{i j}$ are firstorder model, quadratic model, and interaction model coefficients, respectively. The $X_{i}$ and $X_{j}$ are the levels of the independent variables (Tan et al., 2009). The model was evaluated and the analysis included the overall model significance, associated probability, correlation coefficient, $R$, and determination coefficient, $\mathrm{R}^{2}$. Response surface and contour plots were developed using the fully fitted quadratic polynomial equations obtained by holding one of the independent variables with the least effect on the response at a constant value and varying the levels of the other variables within the experimental range (Chu et al., 2004). All statistical tests were carried out with a confidence level of $95.0 \%$.

\section{RESULTS AND DISCUSSION}

\section{Fitting the Model}

The squalene content obtained from all the experiments according to the research surface methodology (RSM) design is listed in Table 2. Experimental yields and squalene content were analysed to get a regression model. The regression model was used to estimate the predicted values, which were compared with the experimental values. In order to check its validity, Table 3 presents the estimated coefficients of the quadratic regression model. A good model should have a significant effect $(p<0.05)$ in predicting the responses, while the lack-of-fit-test should not be significant ( $p>0.05)$, and the coefficient of multiple determination $\left(\mathrm{R}^{2}=0.982\right)$ should be close to 1 , to indicate the agreement between the predicted and experimental values.

The large value of $R^{2}$ (0.919) for squalene content in Table 3 reveals the ability of the model to represent the experimental results. The ANOVA

TABLE 1. CODED LEVELS OF THE INDEPENDENT VARIABLES USED IN THE RESEARCH SURFACE METHODOLOGY (RSM) DESIGN

\begin{tabular}{cccc}
\hline Coded-variables levels $\left(\mathbf{Z}_{\mathbf{j}}\right)$ & Pressure $\left(\mathbf{X}_{1}, \mathbf{M P a}\right)$ & Temperature $\left(\mathbf{X}_{2},{ }^{\circ} \mathbf{C}\right)$ & Holding time $\left(\mathbf{X}_{3}, \mathbf{m i n}\right)$ \\
\hline+1 & 40 & 60 & 40 \\
0 & 30 & 50 & 30 \\
-1 & 20 & 40 & 20 \\
\hline
\end{tabular}


TABLE 2. EXPERIMENTAL SCHEME AND RESULTS OBTAINED FROM RESEARCH SURFACE METHODOLOGY (RSM) FOR THE YIELD AND SQUALENE CONTENT

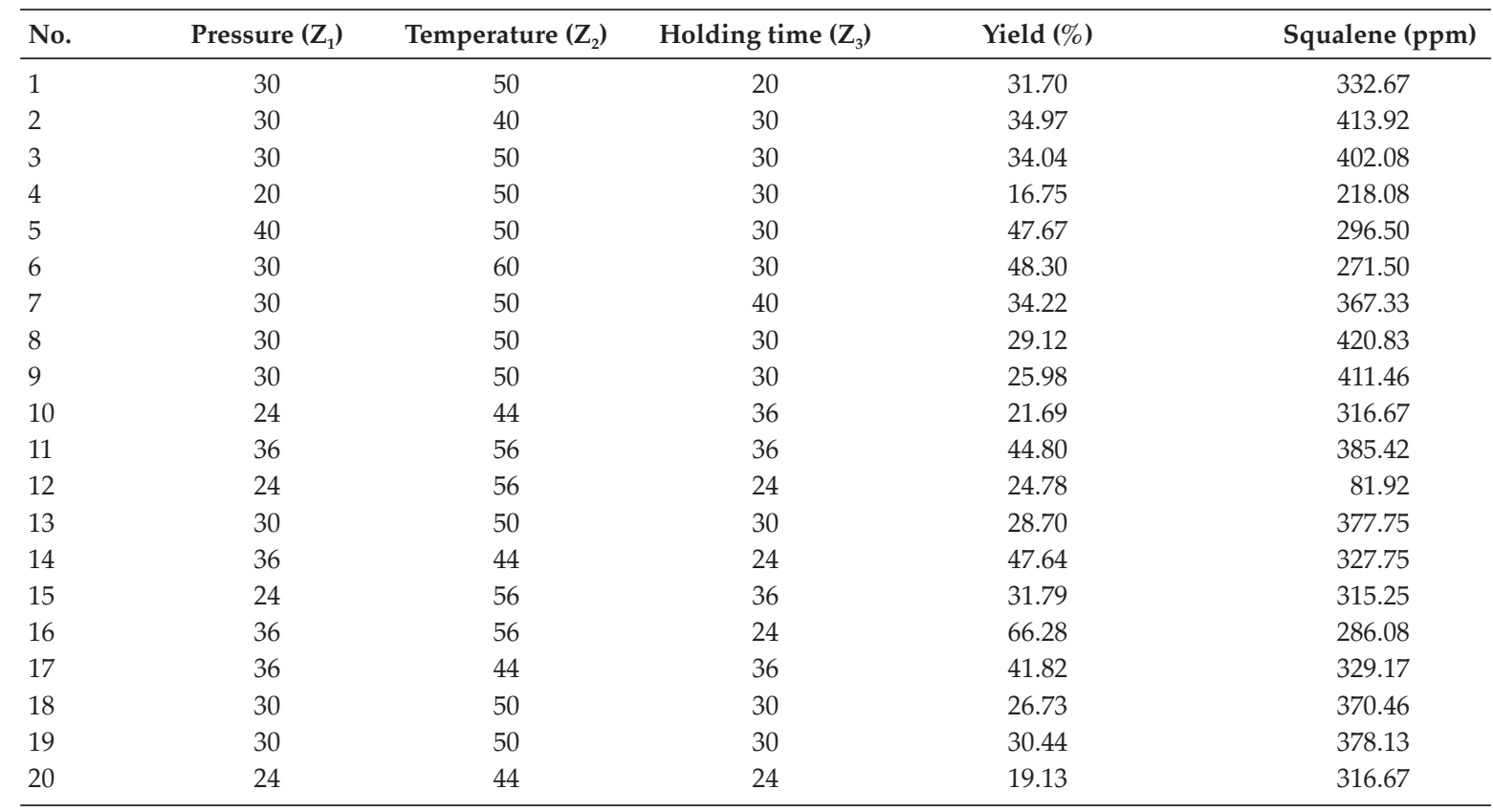

TABLE 3. REGRESSION COEFFICIENTS OF THE FITTED QUADRATIC EQUATION AND STANDARD ERRORS FOR THE YIELD AND SQUALENE CONTENT ${ }^{a}$

\begin{tabular}{lcc}
\hline Regression coefficient & Yield & Squalene content \\
\hline$\beta_{0}$ & 31.183 & 39.316 \\
Linear & 11.523 & 31.948 \\
$\beta_{1}$ & 4.435 & -34.062 \\
$\beta_{2}$ & -1.021 & 29.302 \\
$\beta_{3}$ & & \\
Quadratic & - & -53.876 \\
$\beta_{11}$ & 4.671 & -21.844 \\
$\beta_{22}$ & - & -19.110 \\
$\beta_{33}$ & \\
Interaction & - & 31.344 \\
$\beta_{12}$ & -4.610 & - \\
$\beta_{13}$ & - & 41.406 \\
$\beta_{23}$ & 0.930 & 0.919 \\
$\mathrm{R}^{2}$ & 0.889 & 0.829 \\
$\mathrm{R}^{2}$ (adj) & $0.000^{\mathrm{b}}$ & $0.000^{\mathrm{b}}$ \\
Regression (P value) & $0.245^{\mathrm{c}}$ & $0.090^{\mathrm{c}}$ \\
Lack of fit (P value) & & \\
\hline
\end{tabular}

Note: ${ }^{a} \beta_{\mathrm{i}}$ - the regression coefficient for the main effects. $\beta_{\mathrm{ii}}$ the estimated regression coefficient for the quadratic effects; $\beta_{\mathrm{ij}}$ - the estimated regression coefficient for the interaction effects; 1 - pressure, 2 - temperature and 3 - holding time. bSignificant $(p<0.05)$. ${ }^{c}$ Not significant $(p>0.05)$.

was also used to test for the effect of all parameters as linear, quadratic, or interaction coefficients on the response. As presented in Table 4, the linear term of temperature $(p<0.004)$ was found to be the most significant effect variable for the squalene content. This was followed by the linear terms of pressure $(p<0.005)$ and holding time $(p<0.008)$. The quadratic terms of pressure and temperature were also significant $(\mathrm{p}<0.001$ and $\mathrm{p}<0.031$, respectively). Finally, the interaction terms between temperature and holding time $(p<0.005)$ together with the interaction of pressure and temperature $(p<0.020)$ had a significant effect on the squalene content in PFAD.

\section{Response Surface Analysis of the Model}

The response surface of the model can be projected with three-dimensional plots by varying the two variables and keeping the other variables constant at the central point. Figures 3 and 4 show the squalene content as a function of pressure, temperature, and holding time. Several experiments have been performed at different conditions in order to investigate the effect of parameters on the recovery of squalene from PFAD.

Figure 3 visualises the surface plot of the squalene content as a function of pressure and temperature at $30 \mathrm{~min}$ of fixed holding time. The influence of pressure had a negative quadratic effect on the squalene content. Results indicate that pressure has high impact on the squalene recovery. The squalene content increased with the rise of pressure from 20 to $30 \mathrm{MPa}$. This is most likely due to the increased $\mathrm{CO}_{2}$ density as the pressure increased, which in turn increases the solubility. On the other hand, a further increase of pressure up to $40 \mathrm{MPa}$, resulting to a slightly decreased in the squalene content. This phenomenon can be related to the increased repulsive solute-solvent interactions in the highly compressed $\mathrm{CO}_{2}$ (Gomes et al., 2007).

In the interaction between temperature and pressure, the squalene content rapidly decreases 
TABLE 4. THE p-VALUE AND F RATIO FOR EACH INDEPENDENT VARIABLE EFFECT IN THE POLYNOMIAL RESPONSE SURFACE MODELS ${ }^{a}$

\begin{tabular}{|c|c|c|c|c|c|c|c|c|c|c|}
\hline \multirow[b]{2}{*}{ Variables } & & \multicolumn{3}{|c|}{ Main effects } & \multicolumn{3}{|c|}{ Quadratic effects } & \multicolumn{3}{|c|}{ Interaction effects } \\
\hline & & $X_{1}$ & $X_{2}$ & $X_{3}$ & $X_{1}^{2}$ & $\mathrm{X}_{2}^{2}$ & $\mathrm{X}_{3}^{2}$ & $X_{1} X_{2}$ & $X_{1} X_{3}$ & $X_{2} X_{3}$ \\
\hline \multirow[t]{2}{*}{ Yield $\left(Y_{1}\right)$} & $\begin{array}{c}\mathrm{P} \\
\text { value }\end{array}$ & $0.000^{\mathrm{b}}$ & $0.003^{b}$ & 0.36 & 0.243 & $0.002^{b}$ & 0.165 & 0.603 & $0.009^{b}$ & 0.333 \\
\hline & $\begin{array}{c}\mathrm{F} \\
\text { ratio }\end{array}$ & 10.952 & 4.215 & -0.97 & 1.261 & 4.605 & 1.527 & 0.541 & -3.394 & -1.031 \\
\hline \multirow[t]{2}{*}{$\begin{array}{l}\text { Squalene } \\
\text { content }\left(Y_{2}\right)\end{array}$} & $\begin{array}{c}\mathrm{P} \\
\text { value }\end{array}$ & $0.005^{\mathrm{b}}$ & $0.004^{\mathrm{b}}$ & $0.008^{\mathrm{b}}$ & $0.000^{\mathrm{b}}$ & $0.031^{\mathrm{b}}$ & 0.052 & $0.020^{\mathrm{b}}$ & 0.163 & $0.005^{b}$ \\
\hline & $\begin{array}{c}\mathrm{F} \\
\text { ratio }\end{array}$ & 3.825 & -4.078 & 3.508 & -6.419 & -2.603 & -2.277 & 2.907 & -1.537 & 3.840 \\
\hline
\end{tabular}

Note: ${ }^{a} X_{1}$ and $X_{2}$ the main effect of pressure and temperature, respectively. $X_{1}^{2}$ and $X_{2}^{2}$ the quadratic effect of pressure and temperature, respectively. $X_{1} X_{2}$ the interaction effect of pressure and temperature. ${ }^{b}$ Significant at $p<0.05$.

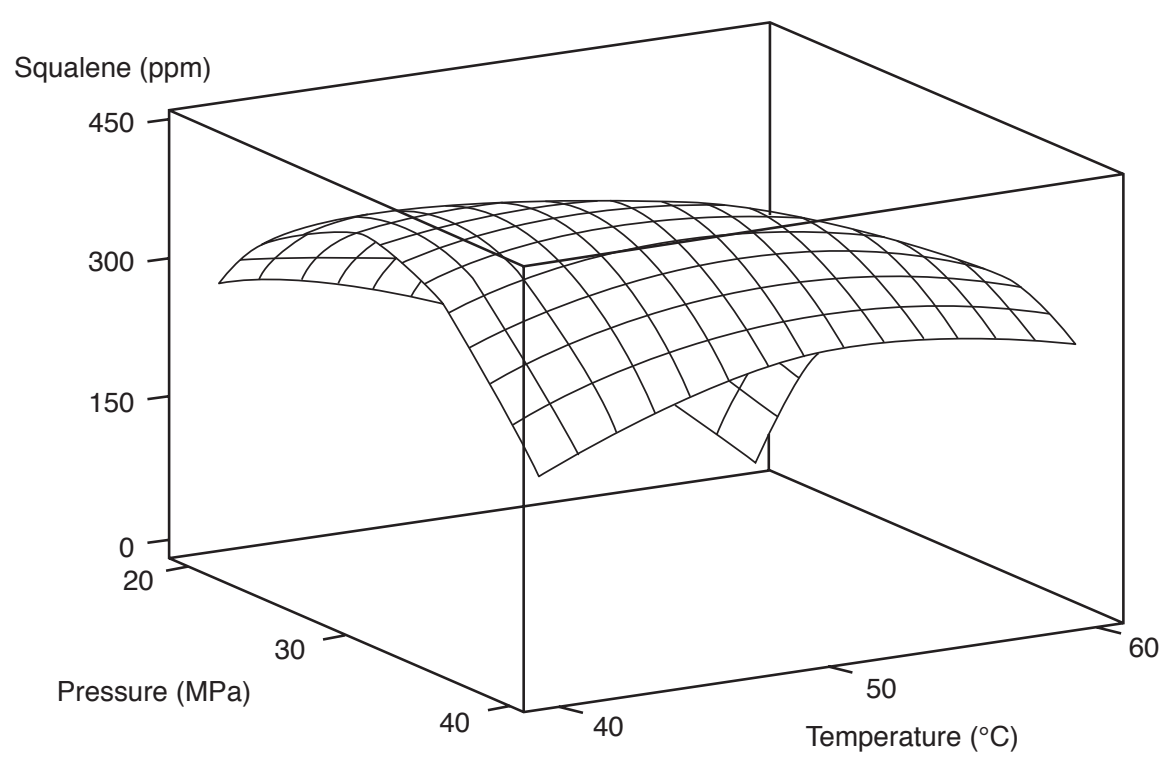

Figure 3. Response surface plot for the effect of pressure and temperature on the squalene content.

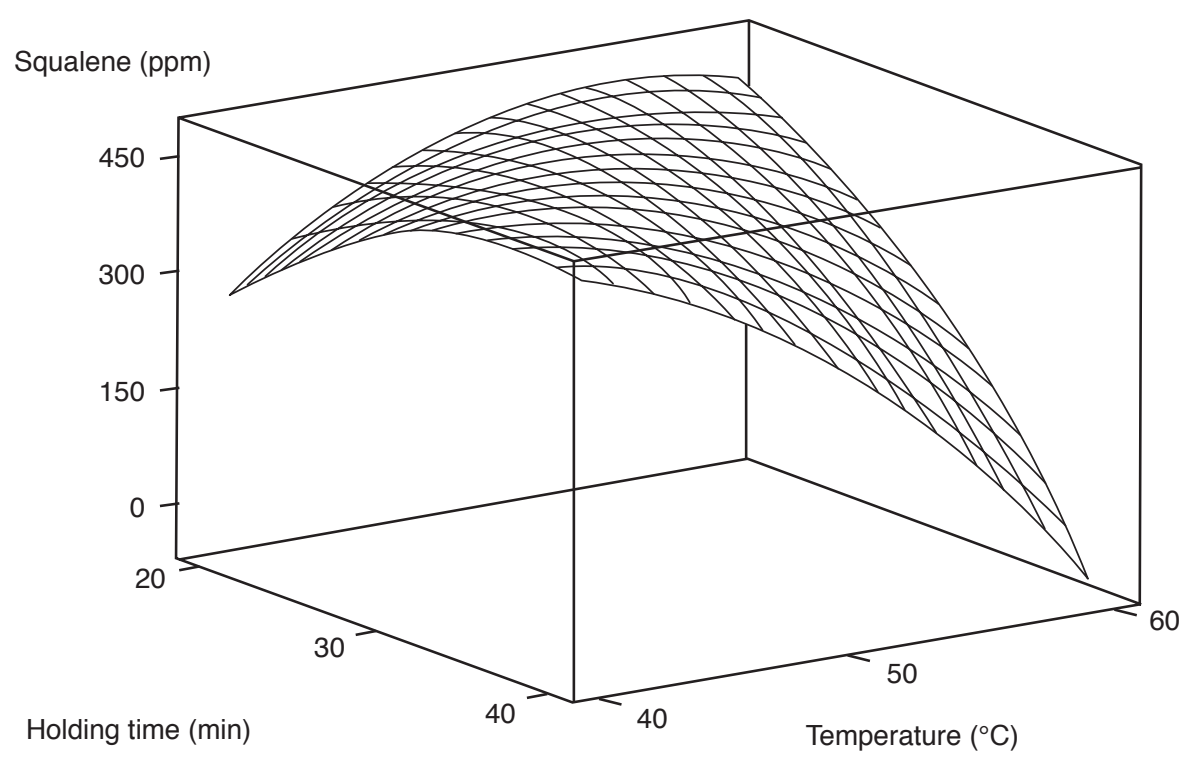

Figure 4. Response surface plot for the effect of holding time and temperature on the squalene content. 
as the temperature increased at low pressures (Figure 3). The reduced density of $\mathrm{CO}_{2}$ at higher temperatures might cause this trend to occur since increasing temperature leads to a decrease in the recovery of squalene. Herein, solvent selectivity plays an important role because it reduces the selectivity of $\mathrm{sc}-\mathrm{CO}_{2}$ towards squalene with increasing solubility (by increasing pressure and decreasing temperature) (Al-Darmaki et al., 2012). Nevertheless, as the pressure increases, particularly above $32 \mathrm{MPa}$, the reducing of squalene content becomes gradually with the increasing temperature. These results showed strong dependence of solubility on the pressure as compared to temperature. This is also reported by Hernández et al. (2010) working on the solubility of binary system squalene- $\mathrm{CO}_{2}$.

To investigate the effect of temperature and holding time on the squalene content, pressure was validated by experiments in triplicate at the optimal conditions. Table 5 lists the verification results for the predicted model. The observed values are in a good agreement with the values predicted from the model.

\section{CONCLUSION}

The second-order polynomial model adequately predicted the response variable of the squalene content for the integrated pressure swing and $\mathrm{sc}-\mathrm{CO}_{2}$ extraction from PFAD. The linear and quadratic of pressure, temperature and holding time had a significant effect on the squalene content. Furthermore, the interactions between pressure and temperature together with the interactions of temperature and holding time also significantly affected the squalene content. The predicted

TABLE 5. PREDICTED AND OBSERVED VALUES FOR THE SQUALENE EXTRACTED FROM PALM FATTY ACID DISTILLATE (PFAD) AT OPTIMUM CONDITIONS

\begin{tabular}{cccccc}
\hline Replication & $\begin{array}{c}\text { Pressure } \\
(\mathbf{M P a})\end{array}$ & $\begin{array}{c}\text { Temperature } \\
\left({ }^{\circ} \mathbf{C}\right)\end{array}$ & $\begin{array}{c}\text { Holding time } \\
(\mathbf{m i n})\end{array}$ & $\begin{array}{c}\text { Yield } \\
(\%)\end{array}$ & $\begin{array}{c}\text { Squalene content } \\
(\mathbf{p p m})\end{array}$ \\
\hline 1 & 23 & 40 & 20 & 19.13 & 386.83 \\
2 & 23 & 40 & 20 & 21.69 & 350.67 \\
3 & 23 & 40 & 20 & 16.75 & 367.33 \\
\hline
\end{tabular}

was kept at constant value of $30 \mathrm{MPa}$ as shown in Figure 4. At a shorter holding time $(20 \mathrm{~min})$, the squalene content decreased as the temperature rose. In contrast, the squalene content increased as the temperature increased when the holding time was $40 \mathrm{~min}$. In principle, the holding time in the pressure swing technique is based on the swelling phenomenon (Hernández et al., 2010; Patel et al., 2006; Smith et al., 1998; Subra et al., 1998). It has been reported that the sample volume expanded by up to $200 \%$ and $50 \%$ for $n$-decane and fish oil methyl esters, respectively, when applying this swing technique (Hernández et al., 2010; Smith et al., 1998). In addition, the effect of the swelling phenomenon on cashew nut shell was studied by Smith Jr et al. (2003) for each single depressurisation. The surface area of cashew nut shell increased the bulk $\mathrm{CO}_{2}$ phase, and so improved the extraction yield (Smith Jr et al., 2003). Thus, the surface area available for $\mathrm{sc}-\mathrm{CO}_{2}$ to penetrate into PFAD increased during the holding time.

Optimisation was performed using a graphical optimisation method to predict the best extraction condition. It showed the overall optimum region was achieved at a pressure of $23 \mathrm{MPa}$ and temperature of $40^{\circ} \mathrm{C}$ with 20 min holding time. Under this optimum set of conditions, the corresponding predicted response of yield and squalene content are 16.75\% and $356.23 \mathrm{ppm}$, respectively. The predicted model optimum extraction parameters using the graphical optimisation method were $23 \mathrm{MPa}, 40^{\circ} \mathrm{C}$, and 20 min holding time. Under such conditions, the yield and squalene content were $19.19 \pm 2.47 \%$ and $368.28 \pm 18.10 \mathrm{ppm}$, respectively. Even though, the yield extracts from this research is higher compared to the previous research $(13.84 \%)$ using continuous $\mathrm{sc}-\mathrm{CO}_{2}$ extraction under optimum condition, the squalene content is slightly lower when applied pressure swing technique (Suleiman et al., 2012). This might be due to the swelling phenomenon during the holding steps in pressure swing technique and further research on these findings is necessary. These findings also suggest that the recovery of squalene is potential for environmental and economical profitable waste management for an additional recovery of value compound from by-product.

\section{REFERENCES}

AL-DARMAKI, N; LU, T; AL-DURI, B; HARRIS, J B; FAVRE, T L F; BHAGGAN, K and SANTOS, R C D (2012). Isothermal and temperature gradient supercritical fluid extraction and fractionation of squalene from palm fatty acid distillate using compressed carbon dioxide. J. Supercritical Fluids Vol. 61: 108-114. 
AZMIR, J; ZAIDUL, IS M; RAHMAN, MM;SHARIF, K M; MOHAMED, A; SAHENA, F; JAHURUL, M H A; GHAFOOR, K; NORULAINI, N A N and OMAR, A K M (2013). Techniques for extraction of bioactive compounds from plant materials: A review. J. Food Engineering Vol. 117 No. 4: 426-436.

BEZERRA, M A; SANTELLI, R E; OLIVEIRA, E P; VILLAR, L S and ESCALEIRA, L A (2008). Response surface methodology (RSM) as a tool for optimization in analytical chemistry. Talanta Vol. 76 No. 5: 965-977.

BHATTACHARJEE, P; CHATTERJEE, D and SINGHAL, R S (2012). Supercritical carbon dioxide extraction of squalene from Amaranthus paniculatus: Experiments and process characterization. Food and Bioprocess Technology Vol. 5 No. 6: 2506-2521.

BONDIOLI, P; MARIANI, C; LANZANI, A; FEDELI, E; MOSSA, A and MULLER, A (1992). Lampante olive oil refining with supercritical carbon dioxide. J. Amer. Oil Chem. Soc. Vol. 69 No. 5: 477-480.

BOONROD,B;PRAPAINAINAR, C;NARATARUKSA, P;KANTAMA, A; SAIBAUTRONG, W; SUDSAKORN, K; MUNGCHAROEN, $\mathrm{T}$ and PRAPAINAINAR, $\mathrm{P}$ (2017). Evaluating the environmental impacts of bio-hydrogenated diesel production from palm oil and fatty acid methyl ester through life cycle assessment. J. Cleaner Production Vol. 142: 1210-1221.

BRUNNER, G (2005). Supercritical fluids: Technology and application to food processing. $J$. Food Engineering Vol. 67 No. 1-2: 21-33.

CHIN, L H; ABDULLAH, A $\mathrm{Z}$ and HAMEED, B H (2012). Sugar cane bagasse as solid catalyst for synthesis of methyl esters from palm fatty acid distillate. Chemical Engineering J. Vol. 183: 104-107.

CHU, B S; BAHARIN, B S; MAN, Y B C and QUEK, $S$ Y (2004). Separation of vitamin E from palm fatty acid distillate using silica: I. Equilibrium of batch adsorption. J. Food Engineering Vol. 62 Issue 1: 97103.

CORZZINI, S C S; BARROS, H D F Q; GRIMALDI, $\mathrm{R}$ and CABRAL, F A (2017). Extraction of edible avocado oil using supercritical $\mathrm{CO}_{2}$ and a $\mathrm{CO}_{2} /$ ethanol mixture as solvents. J. Food Engineering Vol. 194: 40-45.

FORNARI, T; VÁZQUEZ, L; TORRES, C F; IBÁÑEZ, E; SEÑORÁNS, F J and REGLERO, G (2008). Countercurrent supercritical fluid extraction of different lipid-type materials: Experimental and thermodynamic modeling. J. Supercritical Fluids Vol. 45 No. 2: 206-212.
GAPOR MD TOP, A (2010). Production and utilization of palm fatty acid distillate (PFAD). Lipid Technol. Vol. 22: 11-13.

GOMES, P B; MATA, V G and RODRIGUES, A E (2007). Production of rose geranium oil using supercritical fluid extraction. J. Supercritical Fluids Vol. 41 No. 1: 50-60.

HASLENDA, H and JAMALUDIN, M Z (2011). Industry to industry by-products exchange network towards zero waste in palm oil refining processes. Resources, Conservation and Recycling Vol. 55 No. 7: 713-718.

HERNÁNDEZ, E J; SEÑORÁNS, F J; REGLERO, $\mathrm{G}$ and FORNARI, T (2010). High-pressure phase equilibria of squalene + carbon dioxide: New data and thermodynamic modeling. J. Chemical $\mathcal{E}$ Engineering Data Vol. 55 No. 9: 3606-3611.

HOSSEINI, S; JANAUN, J and CHOONG, T S $Y$ (2015). Feasibility of honeycomb monolith supported sugar catalyst to produce biodiesel from palm fatty acid distillate (PFAD). Process Safety and Environmental Protection. Institution of Chemical Engineers. p. 285-295.

ILLE, V (2000). Extraction of coriander seed oil by $\mathrm{CO}_{2}$ and propane at super- and subcritical conditions. J. Supercritical Fluids Vol. 17 No. 2: 177186.

KONCSAG, C I; EASTWOOD, D; COLLIS, A E C; COLES, S R; CLARK, A J; KIRWAN, K and BURTON, K (2012). Extracting valuable compounds from straw degraded by Pleurotus ostreatus. Resources, Conservation and Recycling Vol. 59: 14-22.

LENG, C C S; BAHARIN, B S; MAN, Y C and TAN, C P (2008). Optimisation of enzymatic hydrolysis for concentration of squalene in palm fatty acid distillate. J. Science of Food and Agriculture Vol. 88 No. 9: 1512-1517.

LIU, S; YANG, F; ZHANG, C; JI, H; HONG, P and DENG, C (2009). Optimization of process parameters for supercritical carbon dioxide extraction of Passiflora seed oil by response surface methodology. J. Supercritical Fluids Vol. 48 No. 1: 9-14.

MPOB (2016). Production of crude palm oil for the month of December 2015. http://bepi.mpob. gov.my / index.php / statistics / production / 135production-2015/736-production-of-crude-oilpalm-2015.html

MUBARAK, M; SHAIJA, A and SUCHITHRA, T $\mathrm{V}$ (2015). A review on the extraction of lipid from 
microalgae for biodiesel production. Algal Research. Vol. 7: 117-123.

PAOLO, B; CARLO, M; ARMANDO, L; ENZO, F and ADAM, M (1993). Squalene recovery from olive oil deodorizer distillates. J. Amer. Oil Chem. Soc. Vol. 70 No. 8: 763-766.

PATEL, R N; BANDYOPADHYAY, S and GANESH, A (2006). Extraction of cashew (Anacardium occidentale) nut shell liquid using supercritical carbon dioxide. Bioresource Technology Vol. 97 No. 6: 847-853.

RIGGI, E and AVOLA, G (2008). Fresh tomato packinghouses waste as high added-value biosource. Resources, Conservation and Recycling Vol. 53 No. 1-2: 96-106.

RYAN, E; GALVIN, K; O'CONNOR, T P; MAGUIRE, AR and O'BRIEN, N M (2007). Phytosterol, squalene, tocopherol content and fatty acid profile of selected seeds, grains, and legumes. Plant Foods for Human Nutrition Vol. 62 No. 3: 85-91.

SMITH Jr R L; MALALUAN, R M; SETIANTO, W B; INOMATA, H and ARAI, K (2003). Separation of cashew (Anacardium occidentale L.) nut shell liquid with supercritical carbon dioxide. Bioresource Technology Vol. 88 No. 1: 1-7.

SMITH, R L; YAMAGUCHI, T; SATO, T; SUZUKI, $\mathrm{H}$ and ARAI, K (1998). Volumetric behavior of ethyl acetate, ethyl octanoate, ethyl laurate, ethyl linoleate, and fish oil ethyl esters in the presence of supercritical $\mathrm{CO}_{2}$. J. Supercritical Fluids Vol. 13 No. 1-3: 29-36.

SUBRA, P; CASTELLANI, S; JESTIN, P and AOUFI, $A(1998)$. Extraction of $\beta$-carotene with supercritical fluids Experiments and modelling. J. Supercritical Fluids Vol. 12: 261-269.

SULEIMAN, N; BAHRAIN, B S; HAMED, M and ZAIDUL, I S M (2012). Squalene recovery from palm fatty acid distillate using supercritical fluid extraction. International Food Research J. Vol. 19 No. 4: 1661-1667.

TAN, C H; GHAZALI, H M; KUNTOM, A; TAN, C P and ARIFFIN, A A (2009). Extraction and physicochemical properties of low free fatty acid crude palm oil. Food Chemistry Vol. 113 No. 2: 645-650.

VÁZQUEZ, L; TORRES, C F; FORNARI, T; SEÑORÁNS, F J and REGLERO, G (2007). Recovery of squalene from vegetable oil sources using countercurrent supercritical carbon dioxide extraction. J. Supercritical Fluids Vol. 40 No. 1: 59-66.

WESTERMAN, D; SANTOS, R C D; BOSLEY, J A; ROGERS, J S and AL-DURI, B (2006). Extraction of Amaranth seed oil by supercritical carbon dioxide. J. Supercritical Fluids Vol. 37 No. 1: 38-52.

ZAIDUL, I S M; NORULAINI, N A N; OMAR, A K M; SATO, Y and SMITH, R L (2007). Separation of palm kernel oil from palm kernel with supercritical carbon dioxide using pressure swing technique. J. Food Engineering Vol. 81 No. 2: 419-428. 